\title{
Homogeneity and Sample Preparation from Grams to Microns using NAA, $\mu$ XRF, and SEM-EDS
}

\author{
Abigail P. Lindstrom ${ }^{1}$, Jeffrey M. Davis ${ }^{2}$, Rolf Zeisler $^{1}$, Nicholas WM Ritchie ${ }^{1}$, and Richard M. \\ Lindstrom $^{1}$ \\ 1. National Institute of Standards and Technology, Materials Measurement Laboratory, 100 Bureau \\ Drive, Gaithersburg, MD 20899 USA \\ 2. PNDetector GmbH, Otto-Hahn-Ring 6, 81739 München, Germany
}

When a sample is described as homogeneous, we mean that there is a lack of variation in a measured property over the volume of the sample. The notion of homogeneity is somewhat ill defined because all samples are inhomogeneous at sufficiently small length scales. So to be precise, one must say that a sample is homogeneous to a certain level of variation over a certain length scale. Whether a sample can be considered homogeneous depends upon the application and the length scale, $\mathrm{mm}$ or $\mu \mathrm{m}$.

During Instrumental Neutron Activation Analysis for the certification of NIST SRM 2711a, a soil reference material, excess variability was found in the Al concentration above that expected from counting statistics. Analyses were done by $\mu \mathrm{XRF}$ as an additional test of homogeneity. To investigate further at shorter length scales, we made additional measurements using $\mu$ XRF and SEM-EDS x-ray spectrum imaging.

For two $\mu \mathrm{XRF}$ preparations, one of which was used for spectrum mapping, a small amount of the sample was embedded in epoxy. For one preparation, the bottom of the mount was examined without polishing. For the second mount, the epoxy was polished. The samples were imaged in an Eagle III $\mu \mathrm{XRF}$ system, which has a nominal spot size of approximately $50 \mu \mathrm{m}$. The amount of material probed by the $\mu \mathrm{XRF}$ was significantly smaller than that done by INAA and larger than that done by the SEM (see below).

The polished mount was also investigated by x-ray spectrum imaging on a TESCAN MIRA3 Schottky field emission SEM with 4 Pulsetor silicon drift detectors at $15 \mathrm{keV}, 1 \mathrm{nA}$ and $51.2 \mathrm{~ms} /$ displayed pixel. The point spectra were quantified against standards using NIST DTSA-II [xx] (Figure 2). We also found that there were some differences between the two $\mu$ XRF preparations. The mount that was examined from the bottom of the epoxy was much higher in fines than the other mount where the mount that had been polished, and thus was sampled from a more representative location was less homogeneous. The $\mathrm{x}$ ray spectrum mapping showed a wide variety of compositions and almost no homogeneity at all.

The take-away message is that homogeneity like beauty is in the eye of the beholder. A sample that is homogeneous on one length scale may be well suited for its intended purpose but totally unsuited to other purposes at other length scales. 


\begin{tabular}{|c|c|c|c|c|c|}
\hline & $\mathrm{ppm} \mathrm{Al}$ & \pm & & ppm Al & \pm \\
\hline srm2710a.1a & 59258 & 492 & srm2711a.1a & 67710 & 408 \\
\hline srm2710a.139a & 60141 & 396 & srm2711a.368a & 67698 & 421 \\
\hline srm2710a.483a & 59906 & 649 & srm2711a.484a & 67981 & 429 \\
\hline srm2710a.756a & 58928 & 532 & srm2711a.733a & 67943 & 416 \\
\hline srm2710a.936a & 59701 & 524 & srm2711a.1094a & 65774 & 413 \\
\hline srm2710a.1118a & 59252 & 472 & srm2711a.1342a & 66388 & 447 \\
\hline srm2710a.1255a & 58832 & 479 & srm2711a.1563a & 67129 & 408 \\
\hline srm2710a.1459a & 59725 & 496 & srm2711a.1688a & 67209 & 409 \\
\hline srm2710a.1973a & 60322 & 447 & srm2711a.1212a & 65675 & 411 \\
\hline srm2710a.1973c & 60136 & 502 & srm2711a.1950a & 66569 & 401 \\
\hline srm2710a.1716a & 59179 & 401 & srm2711a.2290a & 66507 & 399 \\
\hline srm2710a.1871a & 59917 & 476 & srm2711a.last.a & 66458 & 404 \\
\hline srm2710a.2061a & 59680 & 512 & & & \\
\hline Wtd mean & 59621 & & & 66912 & \\
\hline Chisq/df & 1.06 & & & 3.77 & \\
\hline
\end{tabular}

Figure 1. The Al concentration after INAA of SRM 2711a and a comparable material SRM 2710a.

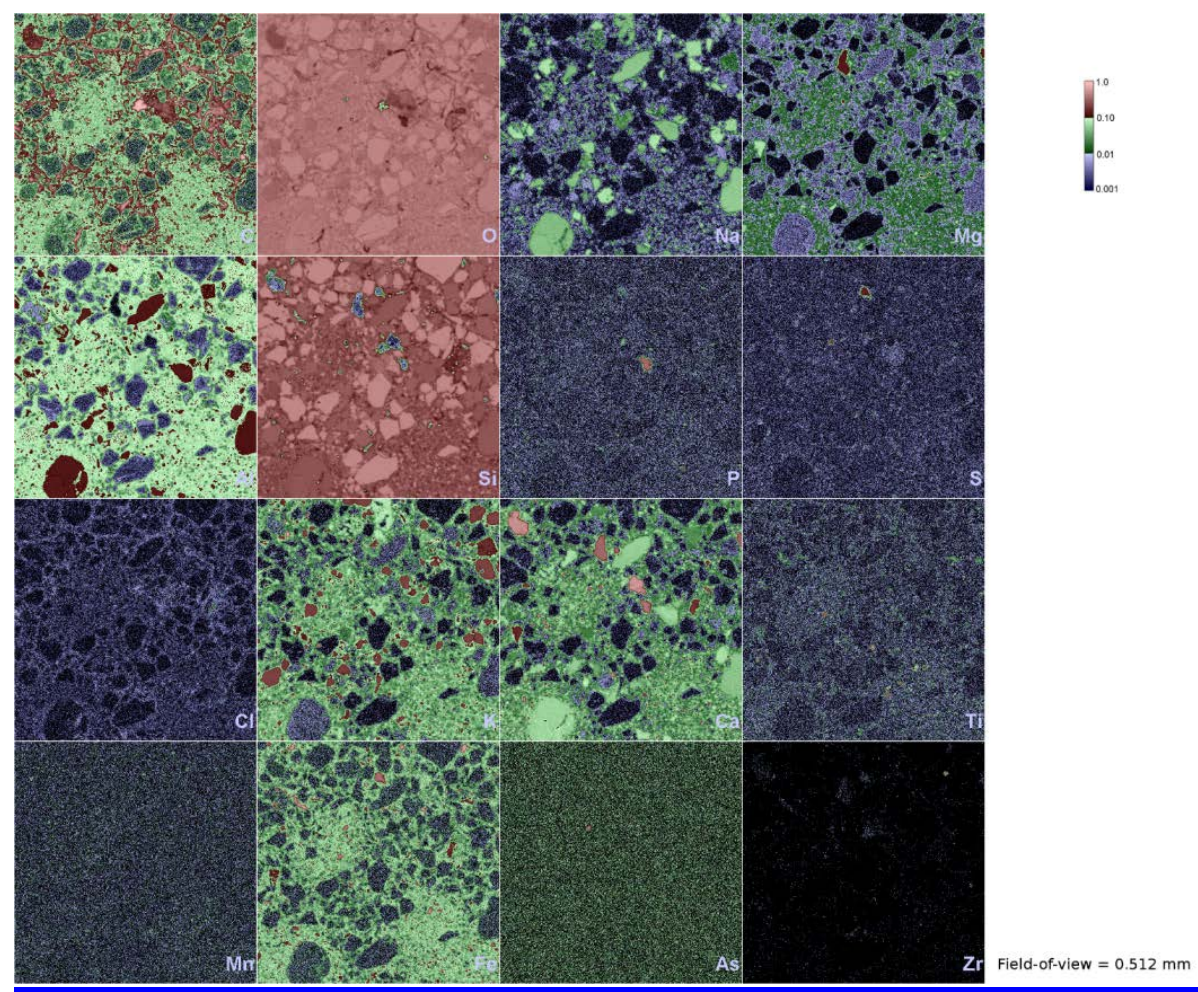

Figure 2. Elemental maps of a region on the polished mount collected on the TESCAN MIRA3 at 15 $\mathrm{keV}$ and $51.2 \mathrm{~ms}$ per displayed pixel $(\mathrm{FOV}=512 \mu \mathrm{m})$. 